School of Finance

University of St.Gallen

ELECTRICITY MARKET COUPLING IN EUROPE: STATUS QUO AND FUTURE CHALlENGES

ROLAND FÜSS

STEFFEN MAHRINGER

MARCEL PROKOPCZUK

WORKING PAPERS ON FinANCE NO. 2015/12

SWISS INSTITUTE OF BANKING AND FINANCE (S/BF - HSG)

August 2015

THIS VERSION: MARCH 2017 


\title{
Electricity Market Coupling in Europe: Status Quo and Future Challenges
}

\author{
Roland Füss, ${ }^{*}$ Steffen Mahringer ${ }^{\dagger}$ and Marcel Prokopczuk ${ }^{\ddagger}$
}

This version: February 2017

\begin{abstract}
In electricity markets globally, market participants and policymakers increasingly focus on integrating adjacent, yet separate market areas via cross-border trade in electricity. Based on a discussion of the institutional framework for organizing cross-border trade, this paper analyzes how spot and futures prices for wholesale electricity are affected by different degrees of market integration. We first contrast the two main mechanisms to allocate transmission capacity between neighboring markets: explicit and implicit auctions. Subsequently, we study the impact of these allocation schemes on the empirical price dynamics of major electricity markets in Europe. Our empirical analysis thereby confirms that under market coupling, economically inefficient cross-border flows in the wrong direction can be avoided. From a policy point of view, however, we show that further market integration can be hindered by individual energy market regulation on a national level, which may be opposed to supra-national frameworks such as market coupling.
\end{abstract}

JEL classification: $Q 4, Q 41, D_{47}$

Keywords: Energy Market Coupling, Electricity Market Reforms, Explicit and Implicit Auction, Price Convergence

\footnotetext{
${ }^{*}$ Swiss Institute of Banking and Finance (s/bf), University of St.Gallen, Unterer Graben 21, 9000 St.Gallen, Switzerland. Email: roland.fuess@unisg.ch (corresponding author).

†Goldman Sachs AG, Friedrich-Ebert-Anlage 49, 60308 Frankfurt am Main, Germany. Email: steffen.mahringer@gs.com.

${ }^{\ddagger}$ School of Economics and Management, Leibniz University Hannover, Koenigsworther Platz 1, 30167 Hannover, Germany. Email: prokopczuk@fmt.uni-hannover.de.
} 


\section{Introduction}

In the aftermath of market liberalization, energy markets in the US and Europe have been undergoing a number of significant structural developments and institutional changes that strongly affect the interplay of supply and demand, and, hence, the general price formation process in these markets. In the case of electricity markets, the rise of exchange-based trading along with regulatory developments (such as the introduction of emissions trading schemes), but also other aspects of market design (such as power exchanges admitting negative prices), have had a marked and long-lasting impact on the price dynamics of spot and derivative contracts. However, the most significant structural change that both US and European electricity markets have seen recently is caused by a general, continued shift towards generation from renewable energy sources.

However, it is not only the volatile nature and general intermittency of renewable generation that makes network integration a demanding task for transmission system operators (TSOs). It is also a problem that, especially for "green" electricity, the location of generation sites may be far away from the actual centers of demand: for instance, with rising numbers of solar panels in Arizona or European wind farms in the North Sea, new ways must be found in order to efficiently direct these electricity flows to high-demand areas which may be thousands of miles away. Hence, increasing interconnectivity - i.e., transmission capacity - between electricity wholesale markets is a crucial prerequisite for a successful integration of renewable generation across both Europe and the US.

Within the European Union (EU), reaching this aim coincides with the intended establishment of the "Internal Electricity Market" (IEM), ${ }^{1}$ an initiative to support further integration of European electricity markets, with the ultimate goal not only to realize uncongested transfer of "green" energy but also to achieve full electricity price convergence across member states. ${ }^{2}$ Fostering integration between national markets, in turn, requires substantial investments in transmission infrastructure both within and across national markets. Already in March 2002, the Barcelona European Council agreed on a minimum

\footnotetext{
${ }^{1}$ See Article 194 of the Lisbon Treaty (Treaty on the Functioning of the European Union) that stipulates to further "(...) promote the interconnection of energy networks."

${ }^{2}$ See, e.g., Article $60(2)$ of Directive 2009/72/EC: "(...) leading, in the long term, to price convergence."
} 
level of interconnectivity between member states of $10 \%$ of installed generation capacities within the respective markets. In this context, the European Network of Transmission System Operators for Electricity (ENTSO-E) estimates that for investment projects of "pan-European significance," a total capital expenditure of approx. EUR 104bn will be required until 2022 (ENTSO-E, 2012).

However, to fulfill the aim of creating a single electricity market across Europe, a well-defined and functioning market model of how to provide access to cross-border transmission capacity is at least as important as further investment into transmission infrastructure. Generally, only few interconnectors in Europe are uncongested, ${ }^{3}$ and over time a variety of different congestion management methods has been developed to govern access to scarce transmission capacity for cross-border trade in electricity. In the past, these allocation mechanisms have primarily relied on explicit ex-ante schemes, where traders first have to acquire transmission capacity in order to then trade in two interconnected, yet institutionally separated, electricity markets. In Europe, in their most widespread form, explicit schemes are usually implemented as (sealed-bid) auction processes where capacity is allocated for different timeframes. ${ }^{4}$ While explicit ex-ante auctions of transmission capacity meet the requirement by the EU that access be provided based on "non-discriminatory market based solutions," 5 they nevertheless lead to an inefficient market design. Among a number of deficiencies, it is primarily the timing sequence of capacity and electricity spot markets that forces traders to acquire cross-border transmission capacity for a given direction before the spread in electricity spot prices between the two respective markets is actually determined. Hence, a trader's decision about both the direction and the amount of transmission capacity to be requested can only be based on an expectation of the price differential between these markets, and in view of generally high levels of volatility in electricity spot markets, this noisy signal

\footnotetext{
${ }^{3}$ For instance, this is the case between Germany and Austria, where transmission capacity is sufficient and no auctioning of rights for interconnector use is required.

${ }^{4}$ Prior to the implementation of market coupling, explicit auction schemes prevailed throughout Europe and were (or still are) used to allocate capacity for exchange between, e.g., England-France, France-Spain, France-Belgium, Belgium-the Netherlands, or the Netherlands-Germany.

${ }^{5}$ See Regulations No. 1228/2003/EC and its follow-up No. 714/2009/EC. Note that this rules out the use of other cross-border congestion management methods, such as rationing or allocation on a "first-come, first-served" basis, given their lack of an inherent market-based mechanism.
} 
may often cause the trader to acquire capacity for the wrong direction.

Since these inefficiencies conflict with the objective of (day-ahead) price convergence within a single pan-European electricity market, the more efficient alternative of implicitly allocating cross-border capacity rights via market coupling is increasingly rolled out across European markets nowadays. Here, markets for transmission capacity and spot electricity are integrated and, hence, clear simultaneously, which allows for an optimal allocation of capacities and results in economically efficient cross-border flows. However, although the previous explicit ex-ante design has already been replaced by an implicit mechanism for a number of interconnectors, it will continue to play a dominant role wherever the harmonization efforts required for market coupling are too high or just infeasible. ${ }^{6}$

In the US, market architecture for most regions is fundamentally different from the uniform (zonal) pricing approach that is prevalent in Europe: instead, nodal pricing (or locational marginal pricing; LMP) has become the standard pricing approach. ${ }^{7}$ In an LMP-based market, the market area is subdivided into numerous pricing points, or nodes, for each of which an individual marginal electricity price is calculated. For instance, in the day-ahead market, participants submit bids and offers for specified point-to-point transactions which are then aggregated and matched by the central market administrator that clears the market. Thus, both day-ahead prices and corresponding flows are determined simultaneously, and in the case of no congestion marginal prices will be equal at each node. ${ }^{8}$ However, it is important to note that this approach optimally addresses transmission constraints within markets only, whereas the above-mentioned problems in efficiently setting up cross-border transactions in Europe also apply for transactions between markets in the US. For instance, if a trader wants to trade in the PJM and NYISO markets, this transaction still needs to be based on an expectation of the price spread, i.e., the price differential between the two markets. As a consequence,

\footnotetext{
${ }^{6}$ Also see, e.g., McInerney and Bunn (2013) on this argument. Moreover, should the market coupling algorithm (that determines the optimal cross-border flows) not be available due to technical problems, the explicit ex-ante scheme will be used as the default option to allocate capacity.

${ }^{7}$ See, e.g., Bohn et al. (1984), Schweppe et al. (1988), and Hogan (1992) for an overview. Nodal pricing (in different forms) has been implemented, e.g., in California (CAISO), Texas (ERCOT), in the Midwest (MISO), New York (NYISO), and New England (ISO-NE) markets, in the PJM Interconnection, and in the Southwest Power Pool (SPP).

${ }^{8}$ Exact price convergence, however, will only be reached if transmission losses are not taken into account or are deemed negligible. Otherwise, even in case of no congestion, prices will still not be equal.
} 
market participants are facing similar problems in organizing efficient cross-border trade as in Europe, making less-than-optimal or even adverse interconnector flows a common problem on both sides of the Atlantic.

In the future, interconnectivity within the still fragmented US electricity grid is generally expected to further increase - e.g., through projects such as the planned "Tres Amigas Superstation," a bundle of three 5-gigawatt (GW) transmission lines that are supposed to unite the three regional grids in the US into a single national grid. ${ }^{9}$ While the market design for this emerging huge trading hub is still being worked out, a solution based on implicit allocation, i.e., market coupling, may likely be expected. ${ }^{10}$

Historically, the literature has looked at the question of how to organize cross-border trading mostly form a theoretical point of view. Bohn et al. (1984), Schweppe et al. (1988) and Hogan (1992) develop a theory of electricity pricing in networks that accounts for the physical properties of electricity. Chao and Peck (1996) extend this analysis and investigate how competition may affect optimal market design. Several studies have shown that market coupling under implicit auctioning leads to a reduction in producers' market power and a reallocation of rents from producers to consumers (Gilbert et al., 2004; Parisio and Bosco, 2008; Ehrenmann and Neuhoff, 2009), but there exist also studies that show that consumers might be hurt by increasing prices due to market coupling (Hobbs et al., 2005). More recently, there have also been some empirical studies. Meeus (2011b) and Parisio and Pelagatti (2014) discuss and analyze the interconnection between Denmark-Germany and Italy-Slovenia, respectively. Finally, Creti et al. (2010) provide some evidence from Italy.

In this paper, we provide a detailed account of the current status of market coupling as a promising and efficient framework to organize the cross-border trade in electricity between adjacent, yet institutionally separated market areas. As such, we contribute to

\footnotetext{
${ }^{9}$ Note that a grid or interconnection is defined as comprising several markets (such as PJM, NYISO, ISO-NE etc. for the Eastern Interconnection) that are electrically tied together and operate at a synchronized frequency. Currently, the three regional grids - the Eastern Interconnection, the Western Electricity Coordinating Council (WECC), and the Electric Reliability Council of Texas (ERCOT) - are only loosely tied together, which impedes, e.g., the transfer of "green" energy generated from wind in Texas or sun in Arizona to centers of high demand within the Eastern Interconnection.

${ }^{10}$ In 2012, Tres Amigas LLC and EPEX Spot have announced a joint cooperation agreement in order to "share mutual expertise in the development and coupling of their respective markets" (EPEX-Spot, 2012). EPEX Spot operates, among others, the coupled electricity spot markets in Germany and France.
} 
the literature in the following ways. First, we give a comprehensive overview of the various institutional frameworks currently in place for cross-border trade between electricity markets. Given that these organizational settings are ultimately of high significance for electricity volumes to be exchanged in the economically efficient direction, we explicitly focus on microstructure effects, such as the timing sequence of traders' decisions when setting up a trade.

Second, we provide substantial empirical evidence of how electricity prices are impacted by the different ways of organizing cross-border exchange between electricity markets. Based on both interconnector flows and corresponding electricity prices in adjacent markets, we contrast explicit and implicit allocation schemes and examine how the workings of either mechanism are reflected in empirical spot price dynamics. For the period under review, our empirical analysis clearly confirms the well-known inefficiencies of explicit allocation schemes (resulting from traders having to acquire transmission capacity before the price differential between the respective market areas has actually been determined), which can effectively be avoided under a market coupling scenario. In addition, however, we broaden the scope of our analysis by also discussing the behavior of futures prices under market coupling, which has so far not been in the focus of extant research.

Third, we assess the current achievements (and drawbacks) of the recent market coupling initiative in Europe from a broader policy perspective. Taking price rigidities in the French market as an example, it becomes obvious that individual electricity market regulation on a national level may easily conflict with a supra-national framework such as market coupling. To our knowledge, this aspect has not been discussed in the literature thus far - and may well warrant further analysis in the future.

The remainder of this paper is structured as follows. Section II outlines the workings of the explicit and implicit schemes in more detail and provides further institutional background for the cross-border trading of electricity. Section III continues the discussion of the two allocation regimes from an empirical point of view by examining in more detail the price dynamics of coupled and non-coupled electricity markets in Europe. Section IV discusses from a policy perspective how the merits and effectiveness of market coupling 
find their boundaries in individual national policies that clearly oppose the idea of the Internal Electricity Market. Section V concludes.

\section{Institutional Background}

In a first step, we qualitatively discuss and compare the two existing allocation schemes in the remainder of this section. This is important since, by its nature, cross-border electricity trade is characterized by a variety of institutional specificities and operational complexities, each of which with significant impact on the topic under consideration. Thereby, several different electricity markets serve as examples for this discussion. We then move on to conduct a detailed empirical analysis of the German-French electricity market where both explicit and implicit allocation schemes have been (or still are) in place. We hence carefully analyze the effect of market coupling by studying price convergence of spot and futures prices in the German-French market before and after the introduction of market coupling. Finally, in a last step, we discuss the issue of policy challenges arising from differences in individual national market designs by using a case-study approach. Here, taking again the French electricity market as an example, we discuss how classic policy intervention can hinder the efficiency of a cross-border trading scheme such as market coupling.

\section{A. Explicit Allocation Schemes}

The generally widespread implementation of explicit allocation mechanisms is mainly due to the fact that they can quickly be set up without requiring a particularly high level of institutional harmonization between adjacent electricity markets. Importantly, as is characteristic of explicit schemes, physical transmission capacity markets and electricity (spot) markets are separated from each other, with the former usually clearing ahead of the latter. Hence, enabling cross-border trade in this way only requires a low degree of integration and joint coordination between both transmission system operators (TSOs) and power exchanges in adjacent markets. This avoids the necessity for a common trading platform and uniform exchange rules, including a simultaneous closing of day-ahead 
auctions for (spot) electricity across markets. However, given that day-ahead prices in both markets are not yet known by the time that traders have to submit their bids for transmission capacity, it generally leads to an inefficient market design. ${ }^{11}$ These inefficiencies manifest in such interconnectors frequently not being used up to their thermal capacity limits or in adverse physical flows, where electricity is directed from a more expensive market to a cheaper connected market. In such a situation, cross-border traders have failed to correctly anticipate the price spread ex-ante, and hence end up having acquired transmission capacity for the "wrong" direction.

From an operational point of view, for most interconnectors, explicitly allocated transmission rights are physical in nature and are assigned for a pre-specified direction of flow (e.g., F $\rightarrow$ GER) and for different timeframes. For instance, prior to the introduction of market coupling at the French-German border, physical transmission rights (PTRs) could be acquired via explicit annual, monthly, and daily auctions. Depending on the timeframe, allocated transmission rights would hence entitle a trader to nominate and physically exchange electricity in a given direction from one market to the other during any hour of the year (month or day, respectively). Figure 1 illustrates in more detail the relevant steps to set up such a cross-border transaction, taking as example the explicit ex-ante auction scheme at the French-German border before it was replaced by market coupling in $2010 .{ }^{12}$ When the holder of a periodic (i.e., monthly or yearly) transmission right wanted to engage in a cross-border transaction on day $t$, the TSO had to be notified by $08: 15$ am on day $t-1$ and provided with a schedule detailing the respective capacities to be nominated during every hour on day $t .{ }^{13}$ In case these capacity holders did not want to trade, their non-nominated capacities originally "earmarked" for periodic transactions were implicitly transferred and added to those capacities to be allocated in the daily market. In that case, according to the "use it or sell it" (UIOSI) principle, traders with monthly or yearly rights received as financial compensation for every megawatt

\footnotetext{
${ }^{11}$ This is a well-documented fact in the literature. Inefficient cross-border trade across various European markets has been analyzed by, e.g., Turvey (2006), Kristiansen (2007), Marckhoff and Muck (2009), Bunn and Zachmann (2010), Bunn and Martoccia (2010), and McInerney and Bunn (2013).

${ }^{12}$ Although auction rules may differ across markets, the overall structure and timeline of the allocation procedure described here can generally be seen as representative of other explicit ex-ante schemes.

${ }^{13}$ See RTE (2009a), p. 17, for transactions between Germany and France.
} 
(MW) of non-nominated capacity the price as determined during the daily auction for the corresponding hour. ${ }^{14}$ Based on the nominations received by the holders of monthly and yearly transmission rights, the TSO then published an update of the available transmission capacity (ATC) that was to be offered on the daily market by 08:45am on day $t-1$; bids for the daily auction then had to be submitted by 09:30am at the latest, and results were released half an hour later. ${ }^{15}$ As already mentioned, this is well ahead of the close of electricity spot (i.e., day-ahead) markets at around noon: 11:00am for the French exchange Powernext and 12:00pm (noon) for its German counterpart EEX at that time. Finally, having been awarded a transmission right in the daily market, traders had to notify the TSO by 02:00pm whether they were going to use it and set up a cross-border transaction on the following day $t$. As opposed to the UIOSI principle, for holders of daily transmission rights, however, the "use it or lose it" (UIOLI) principle applied instead. In the case of non-nomination, this implied that there was no financial compensation; these unused rights were then, in turn, transferred to the intraday market.

With regard to the electricity markets in the US, the institutional design for crossborder (i.e., market-to-market) transactions is less harmonized than in Europe and a variety of different allocation methods coexists, sometimes even at the same border. While a detailed description of these arrangements is beyond the scope of this article, we focus on the following key issues. In view of the nodal pricing system in the US, combining paths of fixed point-to-point transactions would generally allow a trader to ship electricity across states with corresponding path reservations being allocated on a "first-come, firstserve" basis. Given the inherent inefficiency of these fixed allocations, many markets have replaced the physical reservations with a financial transmission rights framework and offer-based export/import scheduling (Spees and Pfeifenberger, 2012). Alternatively, several merchant lines have also been awarded transmission rights which are then re-

\footnotetext{
${ }^{14}$ See RTE (2009b), p. 20.

${ }^{15}$ For further information on the functioning of the capacity daily market under explicit auction schemes, see, e.g., Marckhoff and Muck (2009) who describe the auction design that used to prevail in the capacity daily market at the Dutch-German border: "Investors bid price/volume combinations were several bids per investor are allowed. In case the requested volume is lower than the available capacity, the PTR price is zero. Otherwise, all investors pay the price of the lowest successful bid. If there is more volume requested at the lowest successful bid, the allocation for those bids is partitioned relative to the requested volume."
} 
allocated via long-term contracts or shorter-term auctions. ${ }^{16}$ Nevertheless, irrespective of the precise institutional setting, bid selection and pricing by the independent system operator (ISO) and the physical scheduling of a market-to-market transaction are still two clearly distinct procedures for most electricity markets in the US. Hence, whereas other non-auction based allocation mechanisms may be more common in the US, these mechanisms share a crucial feature of explicit schemes, i.e. of requiring traders to schedule their transactions ex-ante. Even though there are increasing efforts to move the physical scheduling process closer to real-time, ${ }^{17}$ traders still need to rely on an expectation of the price spread between markets, which is - roughly speaking - comparable to the explicit allocation schemes used in Europe.

\section{B. Implicit Allocation Schemes}

By contrast, the concept of market coupling avoids the above timing problem for cross-border traders by clearing capacity and electricity markets simultaneously, i.e., by implicitly allocating transmission rights within the spot auction of electricity in each market. Conceptually, a pricing mechanism that is closely related to market coupling has already been implemented in the Nordic market, Nord Pool, the common electricity market for Norway, Denmark, Sweden, Finland, Estonia, Latvia, and Lithuania. Here, in a first step, the market clearing system price is determined by equating total demand and supply, as aggregated across each national market, thereby ignoring any potential constraints in transmission capacity between bidding areas. ${ }^{18}$ Hence, in the case of no congestion, there is a single price for all bidding areas. Otherwise, depending on the location of the transmission bottleneck(s), the market is "split" into several pricing zones

\footnotetext{
${ }^{16}$ Examples include the Hudson and Linden Variable Frequency Transformer (VFT) interconnectors at the PJM-NYISO border.

${ }^{17}$ For instance, the PJM and NYISO markets have recently proposed "Coordinated Transaction Scheduling" (CTS) where traders have the option to submit a price spread at which they are willing to set up a market-to-market transaction rather than placing individual bids in each market. While this is supposed to enhance economically efficient interconnector use, transactions still need to be scheduled based on an expectation of the spread.

${ }^{18}$ In the Nordic market, national markets are further subdivided into one or more bidding areas, reflecting transmission bottlenecks both within and across national markets. For instance, the Danish market is subdivided into two bidding areas (Western and Eastern Denmark) which are linked by a 600 MW interconnector that is frequently congested.
} 
that are assigned different area prices, and that comprise one or more bidding areas.

The results of the "market splitting" mechanism are in general similar to what is achieved by the variant of market coupling that is currently being implemented between major Western European markets, and that is examined in this study. Yet, in contrast to Nord Pool, it is not a single power exchange that determines (in a "top-down" way) whether to subdivide or retain a single pricing zone across markets. Instead, market coupling is characterized by a more de-centralized ("bottom-up") approach where the joint coordination effort between all involved national TSOs and power exchanges determines which national markets are "coupled" with each other to form a single pricing zone.

Specifically, for every day and each interconnector, TSOs determine the amount of ATC for which the corresponding transmission rights are no longer allocated explicitly but instead assigned to the respective power exchanges in the adjacent markets. In order to achieve spot price convergence, a joint optimization algorithm considers the net import/export positions of each participating exchange for a given clearing price and thus determines the optimal cross-border flows. As such, a buy-order in a higher-priced market can be matched with a sell-order in a cheaper adjacent market, thus mitigating the price differential, with any resulting cross-border flows implicitly covered by the transferred capacity rights. As shown by Meeus et al. (2009) or Weber et al. (2010), the underlying optimization problem can be re-formulated as maximizing overall welfare, constrained by interconnector capacities and other real-time limitations. If one of these constraints is binding - e.g., if the flows necessary to equalize prices exceed the ATC - then prices cannot fully converge and the resulting congestion rent is collected by the owner of the interconnector.

The previously outlined explicit setup at the French-German border was modified when Germany joined the already existing market coupling between France, the Netherlands, and Belgium (the so-called "Trilateral Coupling") on 09-Nov-2010, marking the starting point for the Central Western Europe (CWE) day-ahead market coupling. As a major change to the pre-existing setting, an explicit allocation of transmission rights for interconnector access is henceforth only held for monthly and yearly contracts, whereas on a day-ahead stage all cross-border transmission capacities are available to cover the 
market coupling flows. ${ }^{19}$ Following the harmonization of day-ahead gate closure times (12:00pm noon) at all involved power exchanges, the market coupling algorithm then starts to determine the optimal cross-border flows at around 12:05pm. Finally, the resulting day-ahead prices are published by the CWE power exchanges by 12:55pm. ${ }^{20}$

\section{Empirical Analysis}

\section{A. Ex-Ante Scheduled Transactions in Europe}

The general economic inefficiency of explicit ex-ante schemes is analyzed in Figure 2, where the graph plots the spread between German and French day-ahead power prices against corresponding net transit nominations as a percentage of available interconnector capacity (sample period from 26-Oct-2006 to 09-Nov-2010, i.e. pre-market coupling). Clearly, not only are interconnector capacities often left (partially) unused, although a non-zero price spread in an efficient market setting would call for additional cross-border flow until the price spread was fully exploited or the maximum interconnector capacity was reached. Even worse, out of all nominations, approx. $32 \%$ led to flows in the wrong direction altogether.

On a more detailed level, the data also reveal that during both peak and off-peak hours, French day-ahead power prices exceed German prices more frequently than vice versa - or, more precisely, during approx. $58 \%$ of all hourly periods. ${ }^{21}$ This pattern, in turn, also seems to impact the nomination behavior by cross-border traders: conditional on the spread being negative. In other words, for French day-ahead prices exceeding German prices, net interconnector flows in the economically correct direction (i.e., to the higher-priced market) can be observed during approx. $82 \%$ of all hourly peak and off-peak

\footnotetext{
${ }^{19}$ Note that the transmission capacity of an interconnector is usually "sliced" and allocated for different timescales. Thus, off-exchange transactions, such as customized OTC cross-border trades, can still be executed by traders acquiring monthly or yearly transmission rights, whereas all remaining interconnector capacity can be used by power exchanges for market coupling purposes. Importantly, as pointed out by Meeus (2011a), retaining such a split helps to avoid a potential monopolization of the entire organization of cross-border trade of electricity by the power exchanges participating in market coupling.

${ }^{20}$ See http://www.marketcoupling.com/about-emcc/daily-operations.

${ }^{21}$ Also note that the French-German interconnection, as a series of multiple alternating current (AC) links, has a higher capacity for GER $\rightarrow$ F than for $\mathrm{F} \rightarrow \mathrm{GER}$.
} 
periods. ${ }^{22}$ By contrast, given a positive day-ahead spread (i.e., German prices exceed their French counterparts), the share of net interconnector flows in the right direction is disproportionately lower and correct flows can only be observed during approx. $49 \%$ of all hours. Hence, market participants tend to bet on a negative spread, with a positive spread not only being less frequently observed but apparently also harder to predict correctly.

This diverse picture also manifests itself as regards the degree of net capacity utilization. On an overall basis, interconnectors are used at slightly less than $50 \%$ of their thermal capacity when French power prices exceed German power prices. For the opposite case, average net capacity utilization even gets driven down to less than $10 \%$ since, as mentioned above, adverse flows are observed more frequently. Disaggregating further, we can observe that for a price spread of up to $5 \mathrm{EUR} / \mathrm{MWh}$ (in either direction) and excluding all adverse flows, ${ }^{23}$ French-German interconnectors are still used at only slightly more than $40 \%$ of their thermal capacity. For the complementary case where only price spreads larger than $5 \mathrm{EUR} / \mathrm{MWh}$ are considered, "gross" capacity utilization for flows in the economically correct direction increases to $69 \%$. Clearly, a comparably lower (absolute-level) spread between day-ahead prices increases the likelihood for traders of having predicted it wrongly during the capacity auction and of hence having to engage in an unprofitable trade, which ultimately reduces both gross and net capacity utilization.

A general caveat is in order here: We generally acknowledge that "inefficient" flows from high- to low-priced markets may in the end be caused by loop flows, as they typically occur within highly meshed grids such as in Europe. As such, the above analysis may likely have been subject to related distortions. While it is impossible to mitigate this issue in practice, we point out to a specific pair of markets where loop flows could be excluded from the research design: the British-French interconnection. Bunn and Zachmann (2010) investigate the efficiency of interconnector flows between these two markets and, although avoiding distortions from loop flows, still find that there are evident inefficiencies from

\footnotetext{
${ }^{22}$ Note that in practice, traders may schedule more flows for those hours where they can be sure to properly anticipate the price differential between the markets. Hence, on a volume-weighted basis and conditional on a negative spread, even $93 \%$ of all exchanged MWs have flowed in the correct direction.

${ }^{23}$ By contrast, the previous two examples related to net capacity utilization including adverse flows. In the theoretical case of an interconnector being used up to its full thermal capacity in both directions, the resulting net capacity utilization would then accordingly be $0 \%$.
} 
related interconnector flows in the "wrong" direction. ${ }^{24}$

\section{B. Spot and Futures Prices under the CWE Market Coupling}

The start of the CWE market coupling has fundamentally changed the dynamics of the day-ahead price spreads between Germany-France and Germany-Netherlands, respectively. Figure 3 illustrates this for hours 9 and 18 of the day. For both hourly periods, with few exceptions at mid-November 2010, the spreads are mainly negative or zero, providing clear evidence for interconnector flows henceforth taking economically correct directions - i.e., from the then mainly lower-priced German market to the higher-priced Dutch and French day-ahead markets. The data show that until year-end 2010, exact price convergence was reached in $81 \%$ of all hourly periods for the German-Dutch day-ahead spread and in approx. 52\% of all hours for the German-French spread. Note, however, that for specific hours of the day, these percentages can vary significantly. For instance, for the German-French spread over the same period, German day-ahead prices during hour 24 of the day tend to clearly fall below French prices, so that price convergence could only be reached during less than $23 \%$ of all hours. By contrast, for hour 17 (18), a zero price spread was observed during $80 \%$ (74\%) of all periods.

These patterns also manifest themselves when analyzing the long-term behavior of the day-ahead spread between the German and the Dutch electricity market, as illustrated in Figure 4. For the spread between the prices of electricity to be delivered in both markets during hour 12 (11:00am-12:00pm/noon) on the next day, Figure 4 shows that since the introduction of the CWE market coupling, positive price spreads were no longer observed at all - with very few, notable exceptions. On 27 March 2011, after the close of the day-ahead auction for the following day, the market coupling optimization algorithm could not be run due to a bug in the system which was ultimately caused by the change to daylight-saving time on that day. Consequently, as a fallback mechanism in the case of such a de-coupling, explicit ("shadow") auctions had to be organized in order to allocate

\footnotetext{
${ }^{24}$ In the meantime, the English-French interconnection is no longer the only link between Britain and the Continent. Additional interconnection capacity has been made available, such as BritNed between England and the Netherlands, yet had not been commissioned by the time when Bunn and Zachmann (2010) undertook their study.
} 
the available daily transmission capacity. ${ }^{25}$ For the remaining days, however, the spread was either zero or negative, implying that whenever available transmission capacity is insufficient in order to reach price convergence between the two markets, this applies to flows for the direction GER $\rightarrow \mathrm{NL}$, but not vice versa. More recently, negative spreads have been slightly more prevalent, thus driving down the rate of price convergence, which can be attributed to the steadily growing renewables feed-in in Germany, combined with continued strong levels of natural gas prices affecting the gas-based Dutch electricity market. ${ }^{26}$

Table 1 summarizes the above qualitative observations by providing descriptive statistics for the German-Dutch day-ahead spread during selected hours of the day and for the corresponding baseload spread, i.e. the average of all 24 hourly spreads. The key characteristic of market coupling, i.e., price convergence driving down the spread to zero, is reflected in several of the statistics. For instance, note that a zero baseload spread could be observed for approx. 30\% of all days since 09-Nov-2010, implying that price convergence was not only reached for several hours, but even for all 24 hours on these days. On a more detailed level, we also see that conditional on the spread being negative, both mean and standard deviation tend to be lower. Consequently, since the introduction of market coupling, not only can negative spreads $s^{i}<0$ be observed less frequently, their spikiness is also reduced in terms of absolute size and variation. This change in the dynamics of the spread and, hence of its individual components, can be explained by the fact that under market coupling, supply and demand shocks occurring in the interconnected markets can be mitigated more easily - to the extent that these shocks are non-synchronous. The coordination of cross-border flows between coupled markets always helps to reduce the economic scarcity (abundance) of net supplies that is signaled by electricity prices in one market spiking upwards (downwards). ${ }^{27}$

While the results in Table 1 merely confirm the general working of the basic

\footnotetext{
${ }^{25}$ See, e.g., EPEX-Spot (2011) or CREG (2011). A positive spread could also be observed on 29-Oct2011, which, interestingly again coincides with the clock change back to winter time.

${ }^{26}$ The role of natural gas as marginal fuel in the Dutch market has been further strengthened due to additional exports to Great Britain since the commissioning of the BritNed subsea cable (linking the Dutch with the British market).

${ }^{27}$ See De Jonghe et al. (2008) and Huisman and Kiliç (2013) for an analysis of such volatility reduction potential in the context of the Trilateral Market Coupling between France, Belgium, and the Netherlands.
} 
market coupling idea, i.e., fostering price convergence by achieving economically efficient cross-border trade, these empirical findings - in hindsight - could not have been expected from the outset: Keppler et al. (2014), for example, report a significant deterioration in convergence rates for German and French electricity spot prices for the years post-2012, thereby essentially reversing the increases in welfare that the market coupling mechanism initially had achieved during the years 2011 and 2012. ${ }^{28}$ Taking the German-Dutch border as another example, Platts (2014b) briefly summarizes what can already be seen in Figure 4: A clear deterioration in convergence at this border, too, ultimately driven by "the Netherlands importing Germany's national energy policy in the shape of massive, fluctuating volumes of subsidized green power." As such, the initial performance of the market coupling mechanism right after the beginning of the CWE coupling in end-2010 appears remarkable; yet the drop in convergence rates thereafter raises doubts about its ability in the long-term to mitigate adverse fundamentals underlying each individual market, as evidenced by the massive challenges that the ever-increasing inflow from renewable generation in Germany has put on the entire system.

Finally, as regards the impact of market coupling on futures prices, both empirical findings and theoretical arguments provide a mixed picture thus far. On the one hand, as is well known, it is the non-storability of electricity that causes the classic cost-of-carry relationship between spot and futures prices to break down, which has led to the common perception that electricity has a "split personality" with respect to spot and futures prices (Pilipovic, 1998). As such, the argument that futures prices under market coupling need to converge solely "because spot prices do" does not hold. On the other hand, and regardless of the above, the well-known interpretation of futures prices as expected spot prices at maturity under a suitably chosen (possibly non-unique) pricing measure (Cox and Ross, 1976; Harrison and Kreps, 1979) still holds - also for electricity. Therefore, the fact that the one-year-ahead German-Dutch futures spread in Figure 5 qualitatively tracks the flat and, later on, widening trajectory of the corresponding spot spread during the years

\footnotetext{
${ }^{28}$ Keppler et al. (2014), for instance, estimate that the annual consumer surplus in the French electricity market increased by EUR1.5 billions in 2012.
} 
2011 and 2012 in Figure 4, may be seen to be in line with this reasoning. ${ }^{29}$ Empirically, the average spread between one-year-ahead German and Dutch futures contracts (from 01-Jan-2006 until the start of market coupling) amounts to -4.49 EUR/MWh, whereas the average post-coupling spread has reduced to -1.23 EUR/MWh (0.05 EUR/MWh in 2011 and -2.61 EUR/MWh in 2012). Yet these results remain slightly inconclusive - especially in view of a generally highly non-constant supply side in each of the two markets. ${ }^{30}$ By contrast, the widening of the German-French futures spread since 2012 is not primarily attributable to market-endogenous, fundamental factors, but to an external policy factor, as will further be outlined in the Section IV.

\section{Future Policy Challenges}

With the institutional framework for market coupling now fully laid out, we shall focus on the policy challenges that arise when a supra-nationally organized framework, such as market coupling, meets with the "market realities" in each of the markets that have joined the coupling mechanism. For although the previous analyses have found promising indications that price convergence in European markets may be realized, there are still considerable obstacles to market coupling becoming an actual "success story." First of all, these obstacles have to be seen in the continued scarcity of interconnector capacity a situation that is characteristic for European cross-border trade in electricity and that is furthermore aggravated by massive increases in intermittent (renewable) generation causing congestion on interconnectors even more frequently: Germany's renewable energy policy serves as a prime example here and we refer to Keppler et al. (2014) as one of the first studies that investigates the potential link between increasing, volatile wind and solar feed-in and decreasing price convergence rates within the CWE market coupling. Yet while restrictions in available interconnector capacity (that could help improve convergence rates

\footnotetext{
${ }^{29}$ This simplified argument assumes any potential risk premia to be constant and sets expected spot spreads equal to realized spreads. Further note that although movements in the German-Dutch spot and futures spreads may coincide as displayed in the two figures, Figure 4 only displays the day-ahead spread for hour 12 of the day and not an average baseload spread.

${ }^{30}$ For instance, structural changes such as the German nuclear phase-out or a further continued increase in German renewable generation capacity (that outpaces their European neighbors) may well have been anticipated and reflected in futures prices at that time already, but not in spot prices.
} 
again) and their inherent "drain" on the performance of the market coupling mechanism have to be seen as a given, we want to primarily focus on the policy challenges that a market coupling setting, once fully established and in place, may still face, i.e. irrespective of how interconnector capacities or other market fundamentals are supporting or hindering the functioning of the mechanism: We envisage these challenges primarily emanating from individual electricity market policies on a national level that will inevitably see market coupling run into headwinds to the extent they may even help to preserve price divergence rather than convergence. This section focuses on a prominent example for national electricity market regulation not in accordance with the EU-wide target of promoting the Internal Electricity Market, and highlights from a policy point of view both the reasons and the implications thereof.

The French electricity wholesale market has been integrated into a market coupling framework since 2006, the start of the Trilateral Market Coupling between Belgium, France, and the Netherlands. ${ }^{31}$ Given the strong position of (quasi-) integrated utility Electricité de France (EDF) in both the generation and retail markets, enhancing further competition, especially on the retail side, had been a top priority for policymakers since the liberalization of the French market. ${ }^{32}$ In order to foster retail market entry and enable new suppliers to participate in the cost advantages that EDF enjoyed thanks to its strong nuclear generation position in the wholesale segment, other electricity suppliers were to be supported via a fixed tariff at which they could purchase electricity from EDF. As stipulated by the "NOME" 33 Law passed by the French Government in 2010, EDF is currently required to make available up to $25 \%$ of its nuclear electricity generation to

\footnotetext{
${ }^{31}$ The Trilateral Market Coupling was later extended when the German electricity wholesale market joined the existing arrangement to form the CWE market coupling.

${ }^{32}$ In fact, since the early 2000s, there have been several attempts by the European Commission (EC) to promote further competition on the French retail market. In 2006, it sent out a reasoned opinion to the French Government, complaining about yet incomplete implementation of the Electricity Market Directives. Among a number of issues, the Commission also criticized the "persistence of regulated supply tariffs for eligible clients, which blocks the arrival of newcomers and prevents the free choice of supplier" (EC, 2006). In fact, lower price levels for electricity in the retail market than in the wholesale market back at that time had helped to keep the barriers to entry high for potential alternative electricity suppliers. In 2007, the EC also launched a formal State Aid investigation on French retail electricity tariffs for large and medium-sized companies (EC, 2007). For further information on the French retail electricity market, see, e.g., Creti et al. (2013).

${ }^{33}$ Nouvelle Organisation du Marché de l'Electricité - New Organization of the Electricity Market.
} 
suppliers at a fixed tariff known as ARENH. ${ }^{34}$ The level of this regulated wholesale price is intended to reflect the full cost of nuclear-generated electricity, i.e., essentially EDF's costs for operating and maintaining its nuclear plants as well as reactor life extensions and future upgrades. Hence, by allocating ARENH volumes at such a fixed price to alternative suppliers, their sourcing costs should decrease, thus finally supporting their cost structures to become more competitive vis-à-vis a fully integrated utility such as $\mathrm{EDF}$.

When the ARENH mechanism finally came into effect in July 2011, the tariff had initially been set to $40.00 \mathrm{EUR} / \mathrm{MWh}$ until 01-Jan-2012 and was subsequently increased to today's level of 42.00EUR/MWh. In early 2014, the tariff and its method of calculation were under review, facing several delays as well as a strong political and public debate around the question of what the "proper" costs for EDF's nuclear-generated electricity should be. ${ }^{35}$

From a contractual point of view, ARENH electricity volumes are allocated to retail suppliers on a yearly basis, ${ }^{36}$ so that ARENH's products are most comparable to electricity futures contracts (as opposed to spot contracts). Consequently, practitioners have frequently pointed to the importance of the ARENH tariff as a reference price for the electricity futures market, notably one-year ahead futures contracts. When futures prices for wholesale electricity rise (far) above the tariff, alternative suppliers will source their volumes at the cheaper rate as offered by the ARENH mechanism, thus reducing demand and liquidity at the OTC- and exchange-based forward and futures markets. For the opposite case of wholesale prices falling below the tariff, previously ARENH-sourced volumes have been observed to add to overall wholesale demand, thus driving traded

\footnotetext{
${ }^{34}$ Accès Régulé à l'Electricité Nucléaire Historique - regulated access to historic nuclear energy. Note, however, that the amount of generation to be provided by EDF via the ARENH mechanism is capped at 100 terrawatt hours (TWh).

${ }^{35}$ In this context, also see, e.g., Solier (2010): "Se pose alors la question de l'asymétrie d'information entre le régulateur et l'opérateur historique pour la détermination des coûts supportés par ce dernier."

${ }^{36}$ See, e.g., Commission Decision 2012/C 398/05: "The first period of delivery of regulated access to existing nuclear power started on 1 July 2011. Thirty-two suppliers signed a framework agreement with EDF and 61,3 TWh of regulated access to existing nuclear power were to be delivered between 1 July 2011 and 30 June 2012."
} 
futures prices up to the tariff again. ${ }^{37}$ According to Heren (2014), and following the mechanics described in CRE (2013), some market participants even consider the tariff both as a floor and a cap on futures prices at the same time, which, however, would only be a valid assumption for the theoretical case that the volumes made available under the mechanism were never fully exhausted. In fact, in order to get a sense of the volumes in question, CRE (2013) mentions that "EDF has delivered about 30 TWh to alternative suppliers under ARENH every six months since the mechanism was implemented." 38 At the same time, volumes traded in calendar products ("Y+1 products") in the French market in the first half of 2013 amounted to 57.8 TWh. ${ }^{39}$

The availability of such an alternative sourcing channel (albeit smaller compared to total demand) is even more important when considering the rather limited liquidity of the French electricity wholesale market in general, which has continued to deteriorate also throughout the years covered by our analysis, and especially for yearly products, amongst others. To support this argument, CRE (2013) notes: "Net volumes sold on the wholesale markets were down 30.1 TWh compared to the first half of 2011 mainly due to sales to ARENH in the first half of 2012 (30.2 TWh)." Against this background, the effect of suppliers shifting from one sourcing channel (i.e. market/exchange) to the other (i.e. ARENH) feeds through on wholesale price dynamics more directly. ${ }^{40}$ Moreover, also note that switching between volumes sourced via the ARENH mechanism or via the wholesale market is possible until ARENH volumes communicated to EDF are fixed and binding. In combination, this set-up allows for an obvious arbitrage situation that can lead to remarkable de-coupling of futures prices between Germany and France, as described below.

The impact of the ARENH tariff on price dynamics in the French electricity market became particularly obvious in mid-2013 when French futures prices - previously aligned

\footnotetext{
${ }^{37}$ See CRE (2013), p.63: "When the baseload calendar product market price is over 42 EUR/MWh, ARENH supply substitutes wholesale market purchases for alternative suppliers. However, when the wholesale price is at $42 \mathrm{EUR} / \mathrm{MWh}$ or lower, subscribing to ARENH is called into question by more favourable market conditions." Also see, e.g., Platts (2014a).

${ }^{38}$ See CRE (2013), pg. 43.

${ }^{39}$ See CRE (2013), pg. 30.

${ }^{40}$ See, e.g., de Regulation de l'Energie CRE (2014), pg.81: "Le faible niveau de liquidité a amplifiè le phénomène."
} 
with German futures prices in a general downward movement - kept oscillating around the currently prevailing ARENH threshold, as shown in Figure 6. CRE (2013) accordingly notes: “(...) Therefore, for supply for 2014, this mechanism provides alternative suppliers with trade-off opportunities until 15 November 2013 when alternative suppliers must define the firm quantities they wish to purchase under the ARENH. (...) The stabilisation of French prices at $42 \mathrm{EUR} / \mathrm{MWh}$ in May and June 2013 reflects actions on the market by participants involved in the ARENH mechanism. This mechanism explains the polarisation of transaction around $42 E U R / M W h$." As can be imagined, the oscillating behavior of the French futures price at that time is supported by arbitrage trades of market participants that switch between the two sourcing channels (e.g. selling contracted volumes initially agreed at prices below the ARENH level of $42 \mathrm{EUR} / \mathrm{MWh}$ once the wholesale price would jump above the threshold and vice versa). In addition, suppliers with access to ARENH are effectively assigned a long position in electricity with the strike price of the call option set at the ARENH level of 42 EUR/MWh. Most likely, suppliers therefore have contributed to the above mentioned oscillating price behavior by writing call options, as supposed by de Regulation de l'Energie CRE (2014). Consequently, with French prices at least temporarily supported by the tariff and with German prices continuing their downturn, the futures spread between the two countries has widened significantly in the course of 2013, even exceeding the 6 EUR/MWh threshold in absolute terms.

Clearly, the existence of a fixed-price mechanism, such as the ARENH regime, cannot be in accordance with the aims of the EU to establish a common electricity market across European borders. Although market coupling, from a technical point of view, only targets spot price convergence and does not directly interfere with forward and futures markets, the classic perception of futures prices as expected spot prices nevertheless establishes a link between these markets. Furthermore, although there are various effects on the futures spread when switching to a coupling-based cross-border allocation mechanism, a decoupling of futures prices as displayed in Figure 6 is, of course, not in line with the theory of interconnected electricity markets. From a more general point of view, despite the "split personality" of electricity prices (see Section III), the Internal Electricity 
Market, as envisaged by the EU, should also seek to eliminate differentials in futures prices between coupled markets - especially given that trade in futures contracts still surpasses traded spot volumes by a factor of $5-7 .{ }^{41}$

More generally, this case is a prime example of a market structure deficiency that is caused by the sequential evolution of electricity markets from national isolation towards pan-European integration: While the ARENH mechanism may indeed be instrumental in fostering competition on the retail level, subsequently overlaying such price rigidity with a market coupling framework that essentially relies on wholesale prices adjusting freely, may only yield a suboptimal market design. As such, whereas the implementation of market coupling has also helped to harmonize wholesale spot markets and related institutions across Europe, the generally holistic pan-European focus of the coupling initiative conflicts with non-market-based allocation procedures in individual member states.

In view of the planned further roll-out of market coupling initiatives across Europe, much of the discussion, thus far, has focused on the technical feasibility of this project. With more and more markets joining the coupling, this will require even more powerful mathematical algorithms to solve the optimization problem posed by the coupling process. ${ }^{42}$ However, as highlighted in this example, whenever extending a coupling mechanism by new member states/markets, "soft" criteria such as (i) vertical integration of market participants and (ii) competitiveness in upstream/downstream markets will need to be focused on more strongly than in the past. Otherwise, the idea of a common market zone across multiple countries will only extend to certain markt segments of similar structure across borders and, thus, will necessarily remain incomplete.

\footnotetext{
${ }^{41}$ Based on data provided by CRE (2013) for the French market.

${ }^{42}$ The CWE market coupling is accompanied by other regional coupling initiatives throughout Europe, such as the South-Western Europe (SWE) coupling between France, Spain and Portugal, or the North-Western Europe (NWE) coupling between CWE and the Scandinavian/Baltic countries. Within the "Price Coupling of Regions" (PCR) initiative, these different coupling projects are planned to be integrated in order to finally reach the EU policy goal of a single Internal Electricity Market.
} 


\section{Conclusion}

Creating a common electricity market, one of the top priorities on the energy policy agenda of the EU, is a complex and multifaceted task. Establishing a framework for cross-border trading to exchange surplus generation between adjacent markets generally opens up the possibility for prices across markets to converge under certain conditions and, importantly, for the well-known efficiency gains of free trade to be realized. However, as shown in this paper, the merits of cross-border trading per se can vary dramatically depending not only on market fundamentals but, likewise, on the actual mechanics and institutional design governing the exchange of electricity across markets.

Market coupling schemes have proven very successful as a way to achieve cross-border flows in an economically efficient direction from low-price to high-price markets, thereby avoiding the classic "defect" of explicit allocation schemes which are especially prone to cause inefficient flows in the wrong direction. However, these efficiency enhancements, as reflected in more frequent spot price convergence across markets, do not necessarily translate into converging prices in other segments of the electricity market such as the futures market. As we have seen, individual energy market policies on a national level can act as severe obstacles, albeit temporarily, to the benefits of market coupling being fully realized.

However, the history of electricity markets in Europe shows that individual national (and formerly even isolated) markets had been established well before the idea of creating a single market was put forward by the EU. As such, apart from the technical effort to harmonize an increasing number of markets with different trading platforms, gate closure times and other specificities, market coupling also faces the difficulty of linking historically developed markets that strongly differ in terms of competitiveness along the energy value chain. While not a case for the German or UK retail electricity markets, competition in the French retail market suffers from a highly concentrated market structure where alternative suppliers are granted access to cheaper nuclear generation volumes at a reduced fixed price via the ARENH mechanism. Yet such a tariff represents a classic example of how price rigidities in a single market not only take away liquidity from wholesale spot and futures 
markets, but also help to maintain the very price differences that market coupling actually seeks to eliminate.

In the future, it remains to be seen how the success of market coupling can be preserved despite the increasing number of individual national energy market regulations it will have to accommodate during its further roll-out. Further challenges ahead include, e.g., the reformation of renewables support schemes in countries like Germany, and, moreover, the potential introduction of capacity mechanisms in a number of European markets. As a point in case, the new electricity market design in the UK was among the first to introduce a capacity remuneration mechanism, thus posing a new threat to the efficiencies and welfare gains expected from the pan-European coupling roll-out: under market coupling, how will energy-only markets interact with those markets where capacity payments are in place? New problems are bound to arise given that cross-border flows will no longer be determined by the underlying fundamentals in each respective market, but also by the way how available capacity is remunerated on both sides of the interconnector. $^{43}$ For the US, in a similar manner, ongoing efforts to promote market integration will likely continue to be hindered by regulatory disconnects between different market areas (see, e.g., Section II). Given this outlook, a common energy market policy among EU member states (or across the US) must not only focus on price convergence as key benchmark for the realization of a single electricity market; as a prerequisite to start with, a more holistic approach will instead be required to also focus on the frequently diverging sets of regulations as well as on their idiosyncracies that, at least in the past, have been overlooked too often.

\footnotetext{
${ }^{43}$ See, e.g., Baker and Gottstein (2013) for more information on the problem of "double payments" if an energy-only market is coupled with a market where a capacity remuneration mechanism has been installed.
} 


\section{References}

P. Baker and M. Gottstein. Capacity markets and european market coupling - can they co-exist? Working Paper, 2013.

R.E. Bohn, M.C. Caramanis, and F.C. Schweppe. Optimal pricing in electrical networks over space and time. RAND Journal of Economics, 15(3):360-376, 1984.

D.W. Bunn and M. Martoccia. The Efficiency of Network Transmission Rights as Derivatives on Energy Supply Chains. Journal of Derivatives, 18(2):46-57, 2010.

D.W. Bunn and G. Zachmann. Inefficient arbitrage in inter-regional electricity transmission. Journal of Regulatory Economics, 37(3):243-265, 2010.

H.-P. Chao and S. Peck. A market mechanism for electric power transmission. Journal of Regulatory Economics, 10:25-59, 1996.

J.C. Cox and S.A. Ross. The valuation of options for alternative stochastic processes. Journal of Financial Economics, 3(1-2):145-166, 1976.

Commission de Régulation de l'Energie CRE. Wholesale electricity, CO2, and gas market functioning. 2012-2013 Report, 2013.

Commission de Régulation de l'Electricité et du Gaz; CREG. The price spike on Belpex DAM for 28-03-11. 2011. URL http://www.creg.info/pdf/Etudes/F1099EN.pdf.

A. Creti, E. Fumagalli, and E. Fumagalli. Integration of electricity marktes in europe: Relevant issues for italy. Energy Policy, 38:6966-6976, 2010.

A. Creti, J. Pouyet, and M.E. Sanin. The NOME Law: implications for the French electricity market. Journal of Regulatory Economics, 43(2):196-213, 2013.

C. De Jonghe, L. Meeus, and R. Belmans. Power Exchange Price Volatility Analysis After One Year of Trilateral Market Coupling. Working Paper, Katholieke Universiteit Leuven, 2008.

Commission de Regulation de l'Energie CRE. Wholesale electricity, CO2, and gas market functioning. 2013-2014 Report, 2014.

EC. The Commission takes action against Member States which have still not properly opened up their energy markets. Press Release (IP/06/1768), 2006.

EC. State aid: Commission opens investigation into regulated electricity tariffs in France. Press Release (IP/07/815), 2007. 
A. Ehrenmann and K. Neuhoff. A comparison of electricity market designs in networks. Operations Research, 57:274-286, 2009.

ENTSO-E. Ten-Year Network Development Plan. 2012. URL https://www.entsoe.eu/ major-projects/ten-year-network-development-plan/tyndp-2012.

EPEX-Spot. 27 March 2011 CWE Incident - Public message to the market parties. 2011. URL http://static.epexspot.com/document/12668/CWE_MC_SC_1107-04d_ Communication_to_market_parties_final.pdf.

EPEX-Spot. Joint Cooperation Agreement Executed Between EPEX Spot And Tres Amigas. 2012. URL http://static.epexspot.com/document/17470/2012-01-10_ Tres\%20Amigas_EPEXSPOT.pdf.

R. Gilbert, K. Neuhoff, and D. Newbery. Allocating transmission to mitigate market power in electricity networks. RAND Journal of Economics, 35:691-709, 2004.

J.M. Harrison and D.M. Kreps. Martingales and arbitrage in multiperiod securities markets. Journal of Economic Theory, 20(3):381-408, 1979.

ICIS Heren. New French ARENH electricity tariff calculation delayed. Market Commentary for 27 February 2014, 2014.

B.F. Hobbs, A.M. Rijkers, and M.G. Boots. The More Cooperation, The More Competition? A Cournot Analysis of the Benefits of Electric Market Coupling. The Energy Journal, 26(4):69-97, 2005.

W.W. Hogan. Contract Networks for Electric Power Transmission. Journal of Regulatory Economics, 4(3):211-242, 1992.

R. Huisman and M. Kiliç. A history of European electricity day-ahead prices. Applied Economics, 45(18):2683-2693, 2013.

J.H. Keppler, S. Phan, Y. Le Pen, and C. Boureau. The impact of intermittent renewable production and market coupling on the convergence of french and german electricity prices. CEEM Working Paper 2014-07, 2014.

T. Kristiansen. An assessment of the German-Danish cross-border auctions. Energy Policy, 35(6):3369-3382, 2007.

J. Marckhoff and M. Muck. Jump Risk Premia in Short-Term Spread Options: Evidence from the German Electricity Market. Working Paper, University of Bamberg, 2009. 
C. McInerney and D.W. Bunn. Valuation anomalies for interconnector transmission rights. Energy Policy, 55:565-578, 2013.

L. Meeus. Why (and how) to regulate power exchanges in the EU market integration context? Energy Policy, 39(3):1470-1475, 2011a.

L. Meeus. Implicit auctioning on the Kontek Cable: Third time lucky? Energy Economics, 33(3):413-418, 2011b.

L. Meeus, L. Vandezande, S. Cole, and R. Belmans. Market coupling and the importance of price coordination between power exchanges. Energy, 34(3):228-234, 2009.

L. Parisio and B. Bosco. Electricity prices and cross-border trade: Volume and strategy effects. Energy Economics, 30:1760-1775, 2008.

L. Parisio and M. Pelagatti. Market coupling between electricity markets: theory and empirical evidence for the Italian-Slovenian interconnection. 11th International Conference on the European Energy Market, Krakow, 2014.

D. Pilipovic. Energy Risk: Valuing and Managing Energy Derivatives. McGraw-Hill, New York, 1998.

Platts. French prompt stronger as reactor delayed. Market Commentary for 02 April 2014, 2014a.

Platts. Cwe convergence down despite coupling. European Power Daily, 2014b.

RTE. Access Rules for Imports and Exports on the French Public Power Transmission System. 2009a. URL http://clients.rte-france.com/lang/an/clients_traders_ fournisseurs/services_clients/inter_contrats.jsp.

RTE. Rules for Capacity Allocation by Explicit Auctions within Central West Europe Region (CWE Auction Rules). 2009b. URL http://clients.rte-france. com/lang/an/clients_traders_fournisseurs/services_clients/initiatives_ regionales.jsp.

F.C. Schweppe, M.C. Caramanis, R.D. Tabors, and R.E. Bohn. Spot Pricing of Electricity. Kluwer Academic Publishers, Boston, MA, 1988.

B. Solier. La Réforme du Marché de l'Electricité Français: Quels Impacts pour la Tarification et la Concurrence? Les Cahiers du PREC, 4. Paris: Série Information et débats, 2010. 
K. Spees and J. Pfeifenberger. Seams Inefficiencies - Problems and Solutions at Energy Market Borders. Presentation by The Brattle Group, 2012.

R. Turvey. Interconnector economics. Energy Policy, 34(13):1457-1472, 2006.

A. Weber, D. Graeber, and A. Semmig. Market Coupling and the CWE Project.

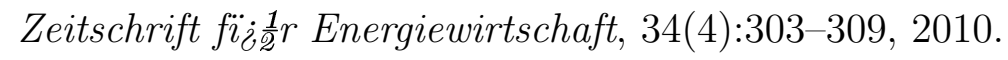




\section{Table 1: Descriptive Statistics: GER-NL Day-Ahead Spread}

This table reports summary statistics for the spread $s^{i}$ between day-ahead electricity prices in Germany and the Netherlands for selected hours of the day $(i=\{6,9,12,15,18,21\})$. The baseload spread (s ${ }^{\text {base }}$; "Base") is defined as the (unweighted) arithmetic average of all 24 hourly spreads on a given day. The "Pre-Market Coupling" sample covers the period from 01-Jan-2002 until 08-Nov-2009. The "Post-Market Coupling" sample covers the period thereafter until 31-Dec-2012.

Mean $^{+}$and Std. Dev. ${ }^{+}$are defined as $\mu^{+}=\mathbb{E}\left[s^{i} \mid s^{i}>0\right]$ and $\sigma^{+}=\sqrt{\mathbb{E}\left[\left(s^{i}-\mu^{+}\right)^{2} \mid s^{i}>0\right]}$, respectively. Note that spreads beyond a threshold of $500 \mathrm{EUR} / \mathrm{MWh}$ were excluded from the samples in order to avoid distortions. All data is sourced from Bloomberg.

\begin{tabular}{|c|c|c|c|c|c|c|c|c|}
\hline \multicolumn{2}{|c|}{ Hour of Day } & 6 & 9 & 12 & 15 & 18 & 21 & Base \\
\hline \multirow{14}{*}{ 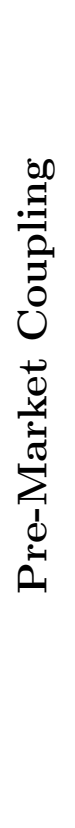 } & $\mathrm{n}$ & 3234 & 3234 & 3225 & 3229 & 3205 & 3234 & 3234 \\
\hline & $s^{i}<0$ & $33.6 \%$ & $52.3 \%$ & $69.2 \%$ & $73.1 \%$ & $65.5 \%$ & $61.9 \%$ & $68.6 \%$ \\
\hline & $s^{i}=0$ & $0.4 \%$ & $0.1 \%$ & $0.2 \%$ & $0.2 \%$ & $0.1 \%$ & $0.3 \%$ & $0.0 \%$ \\
\hline & Mean & 2.01 & -2.45 & -15.09 & -9.10 & -12.07 & -4.44 & -4.84 \\
\hline & Mean $^{+}$ & 5.34 & 6.58 & 7.89 & 5.64 & 6.29 & 3.83 & 3.30 \\
\hline & Mean $^{-}$ & -4.50 & -10.66 & -25.31 & -14.51 & -21.75 & -9.51 & -8.57 \\
\hline & Median & 1.81 & -0.32 & -3.90 & -3.02 & -2.00 & -1.55 & -1.83 \\
\hline & Min & -129.47 & -464.17 & -481.07 & -477.09 & -480.13 & -376.49 & -154.98 \\
\hline & Max & 43.11 & 256.84 & 345.05 & 430.09 & 412.31 & 70.14 & 74.63 \\
\hline & Std. Dev. & 7.13 & 21.97 & 46.34 & 33.84 & 47.07 & 15.31 & 13.47 \\
\hline & Std. Dev. ${ }^{+}$ & 4.94 & 13.45 & 19.82 & 18.96 & 19.79 & 4.92 & 6.10 \\
\hline & Std. Dev. ${ }^{-}$ & 6.25 & 24.83 & 50.90 & 36.43 & 53.93 & 17.21 & 14.27 \\
\hline & Skewness & -2.03 & -6.83 & -4.58 & -6.15 & -4.97 & -8.08 & -4.17 \\
\hline & Kurtosis & 39.29 & 141.51 & 35.15 & 79.64 & 40.01 & 138.19 & 32.41 \\
\hline \multirow{14}{*}{ 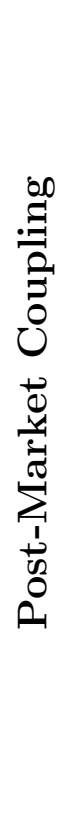 } & $\mathrm{n}$ & 784 & 784 & 784 & 784 & 784 & 784 & 784 \\
\hline & $s^{i}<0$ & $14.7 \%$ & $15.1 \%$ & $35.1 \%$ & $38.5 \%$ & $24.9 \%$ & $24.1 \%$ & $60.5 \%$ \\
\hline & $s^{i}=0$ & $83.0 \%$ & $82.7 \%$ & $64.5 \%$ & $61.4 \%$ & $73.5 \%$ & $74.4 \%$ & $30.2 \%$ \\
\hline & Mean & -1.77 & -1.17 & -4.22 & -4.92 & -3.00 & -2.70 & -3.11 \\
\hline & Mean $^{+}$ & 2.38 & 12.15 & 2.92 & 0.75 & 9.10 & 5.07 & 0.77 \\
\hline & Mean $^{-}$ & -12.47 & -9.64 & -12.05 & -12.78 & -12.67 & -11.53 & -5.25 \\
\hline & Median & 0.00 & 0.00 & 0.00 & 0.00 & 0.00 & 0.00 & -0.50 \\
\hline & Min & -217.23 & -40.15 & -76.90 & -139.76 & -57.39 & -57.04 & -89.43 \\
\hline & Max & 7.02 & 30.01 & 5.41 & 0.75 & 28.58 & 9.86 & 8.23 \\
\hline & Std. Dev. & 11.58 & 5.47 & 8.39 & 9.63 & 7.82 & 6.88 & 6.67 \\
\hline & Std. Dev. ${ }^{+}$ & 2.03 & 10.30 & 2.25 & n.a. & 7.26 & 3.33 & 1.38 \\
\hline & Std. Dev. ${ }^{-}$ & 28.01 & 8.80 & 10.31 & 11.85 & 10.63 & 9.57 & 7.85 \\
\hline & Skewness & -15.45 & -2.17 & -2.92 & -4.83 & -2.89 & -3.16 & -6.43 \\
\hline & Kurtosis & 273.80 & 17.34 & 12.17 & 50.54 & 11.09 & 12.47 & 69.76 \\
\hline
\end{tabular}




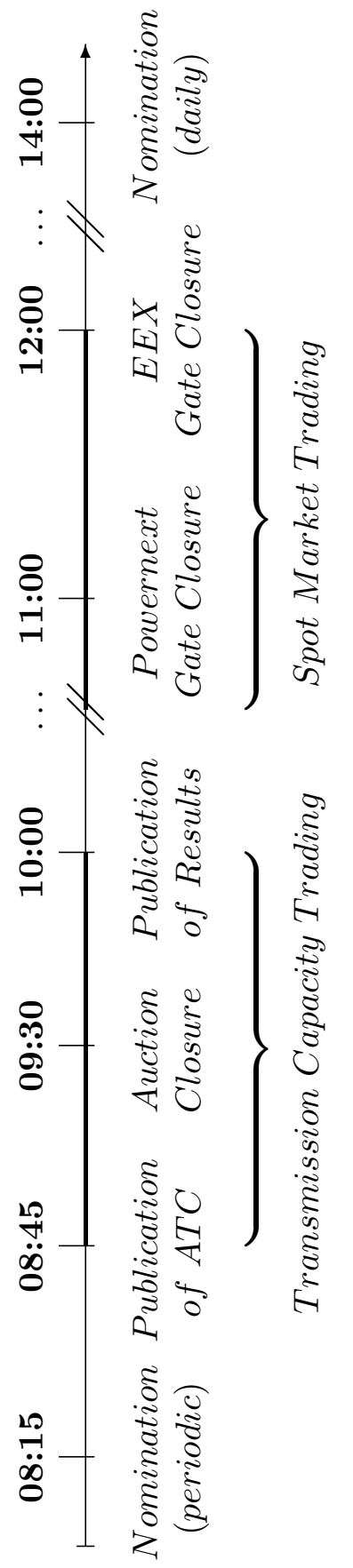

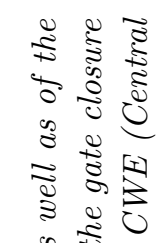

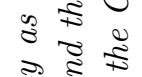

हु है के

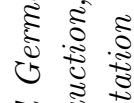

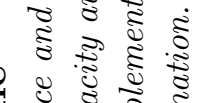

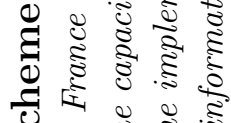

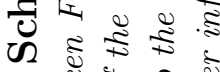
ป - 0 吾 U. స્心 过 责

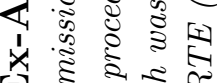

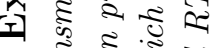

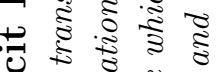

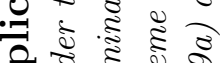

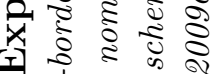
के कू बै

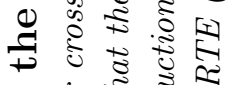
$\dot{0} \approx$ ๘ 诺

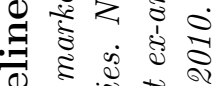

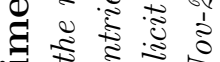

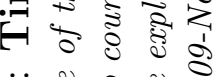

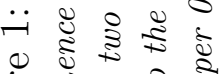

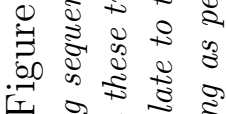

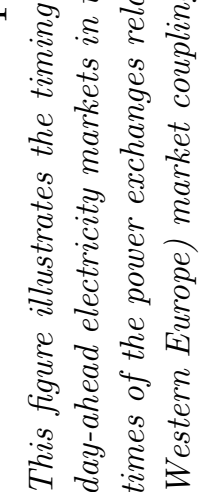




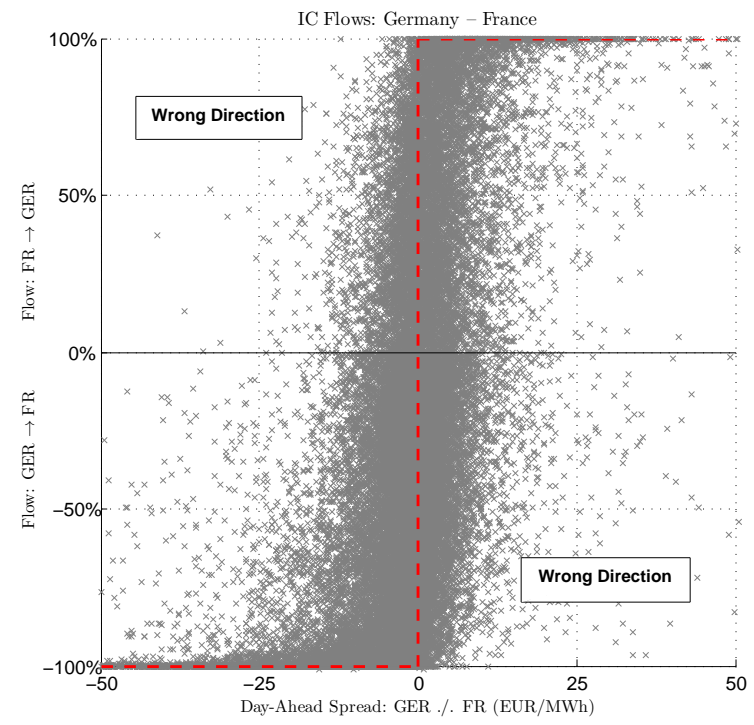

\section{Figure 2: Interconnector Flows: Germany - France}

This figure illustrates inefficient interconnector use by plotting the day-ahead price spread between the German and French electricity markets versus net transit nominations (as a percentage of interconnector capacity) for the same hours. Data shown for the period from 26-Oct-2006 to 09-Nov-2010. The dashed line indicates economically efficient flows (as would have occurred under market coupling) such that there is no flow in the wrong direction, nor less-than-optimal flow in the right direction. Source: RTE (http://clients.rte-france.com) and Bloomberg. 

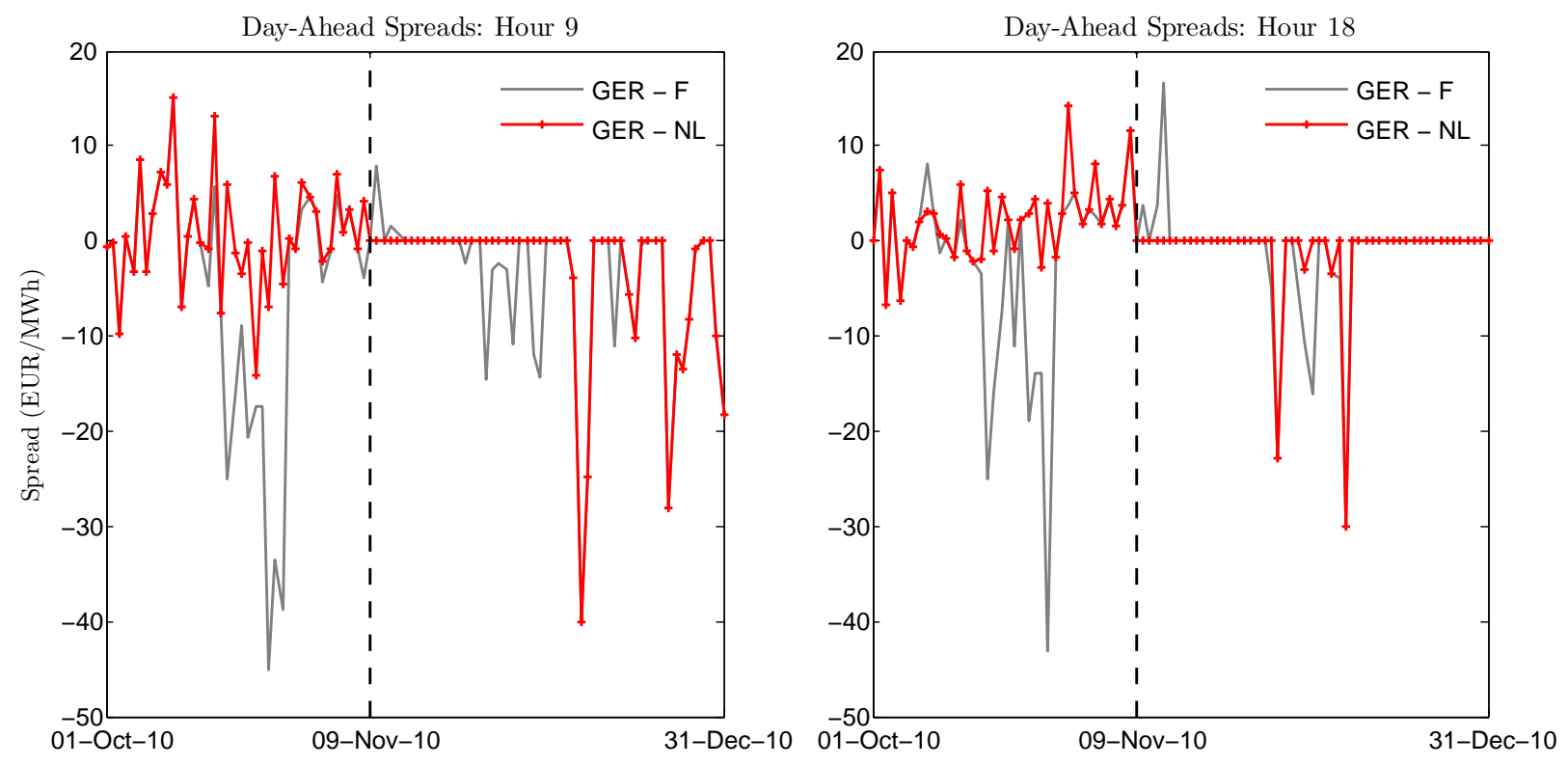

Figure 3: Spread in Day-Ahead Prices: GER - F and GER - NL

This figure shows the spread in day-ahead electricity prices between Germany and France as well as Germany and the Netherlands. The LHS graph displays day-ahead prices for hour 9 of the day (8:00-9:00am), whereas the RHS graph relates to hour 18 (5:00-6:00pm). The vertical dashed line marks the start of the CWE (Central Western Europe) market coupling between Germany, France, the Netherlands, and Belgium as per 09-Nov-2010. All data is sourced from Bloomberg. 


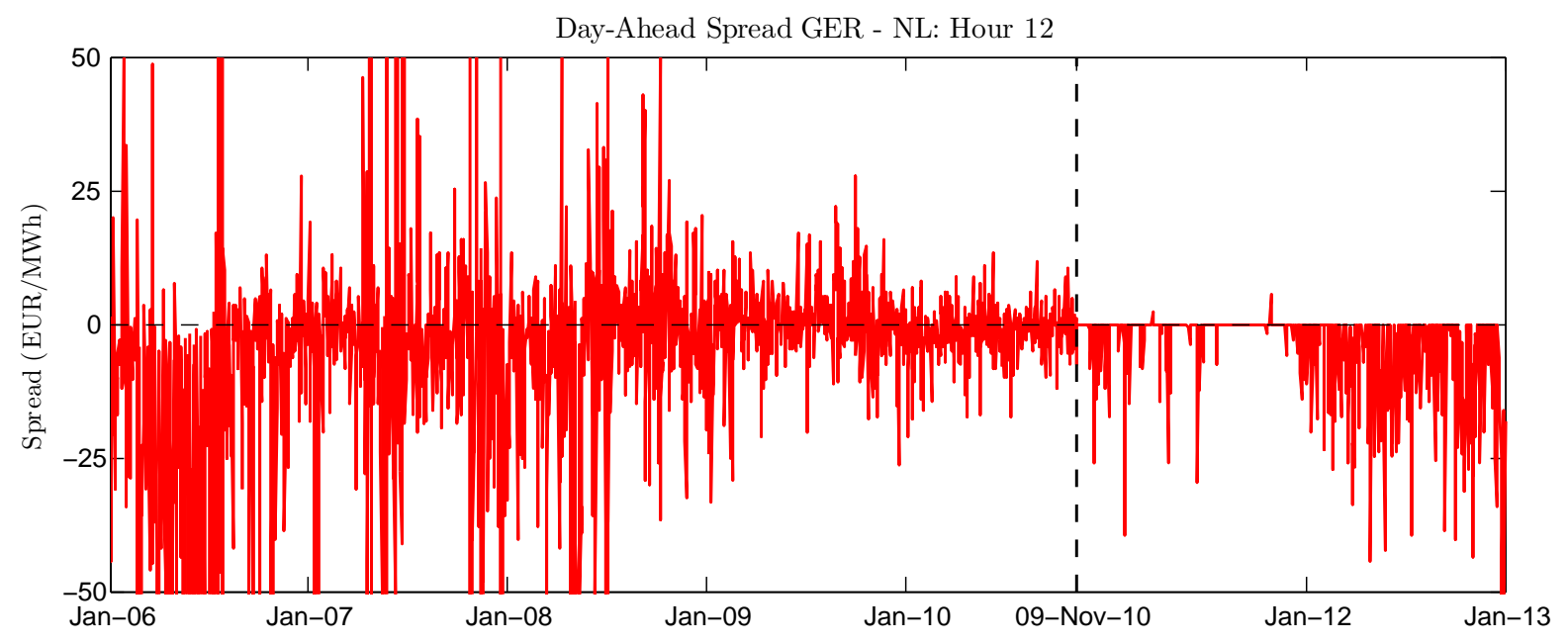

Figure 4: Spread in Day-Ahead Prices: Germany-Netherlands

This figure shows the spread in day-ahead electricity prices between Germany and the Netherlands during the period from 01-Jan-2006 to 31-Dec-2012. The underlying day-ahead prices relate to hour 12 of the day (11:00am-12:00pm). The vertical dashed line marks the start of the CWE (Central Western Europe) market coupling between Germany, France, the Netherlands, and Belgium as per 09-Nov-2010. All data is sourced from Bloomberg. 


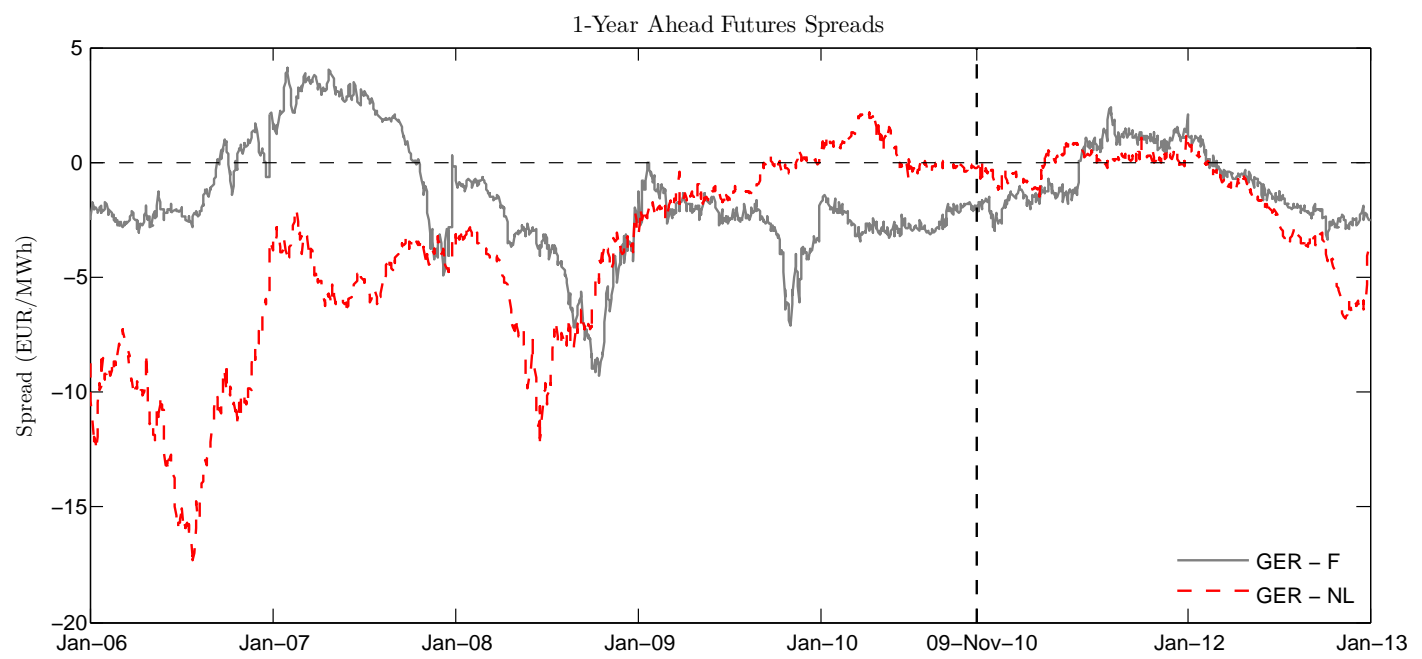

Figure 5: Spread in 1-Year Ahead Futures Prices: GER-F and GER-NL

This figure shows the spread in (generic) one-year-ahead futures contracts between Germany and France as well as Germany and the Netherlands during the period from 01-Jan-2006 to 31-Dec2012. The vertical dashed line marks the start of the CWE (Central Western Europe) market coupling between Germany, France, the Netherlands, and Belgium as per 09-Nov-2010. All data is sourced from Bloomberg. 

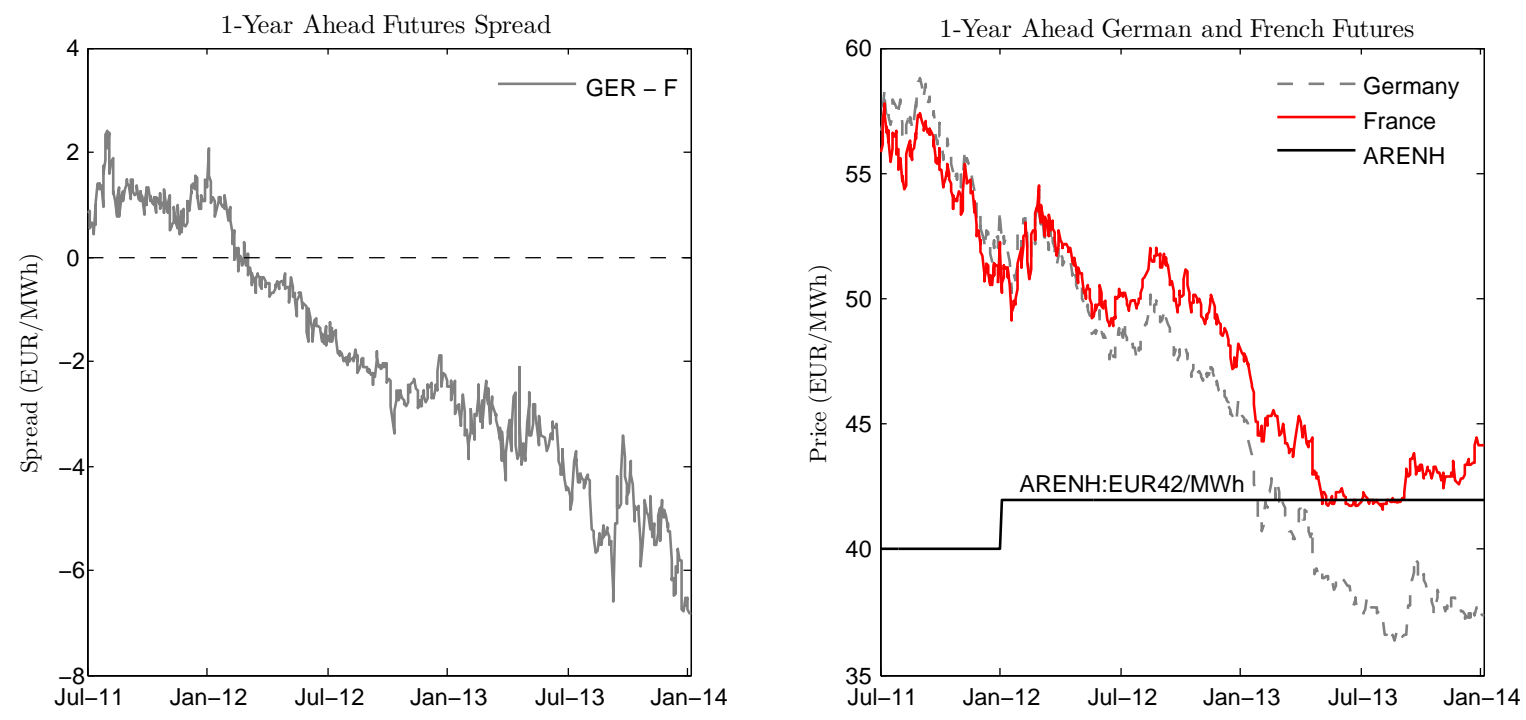

Figure 6: One-Year-Ahead Futures and Futures Spreads: Germany-France The RHS graph shows the development of French and German one-year-ahead baseload futures prices between July-2011 and January-2014. The LHS graph shows the corresponding spread between the two contracts, defined as German-French electricity price differential. 